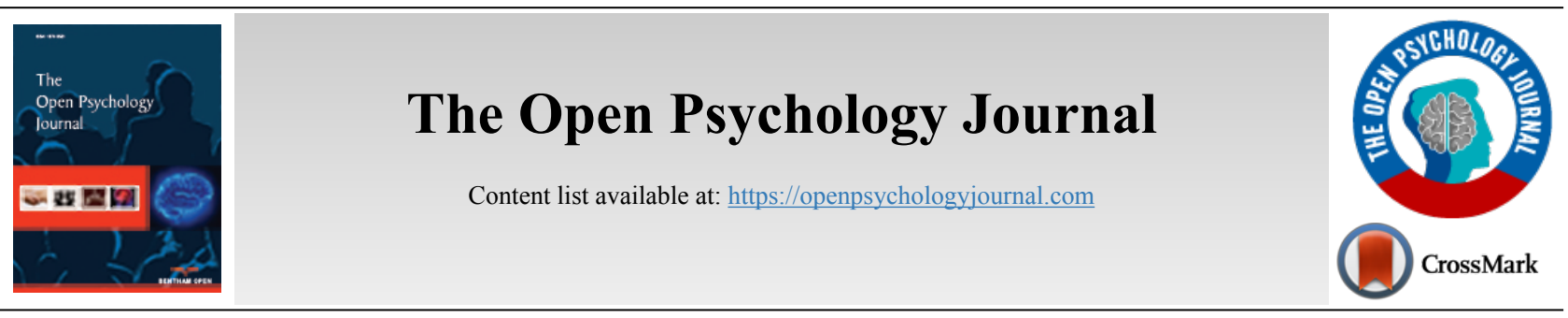

RESEARCH ARTICLE

\title{
Satisfaction with Singlehood in Never-Married Singles: The Role of Gender and Culture
}

Dominika Ochnik $^{1, *}$ and Gal Slonim ${ }^{2}$

${ }^{1}$ Institute of Psychology, University of Opole, Opole, Poland

${ }^{2}$ Institute of Psychology, Department of Psychology, University of Potsdam, Potsdam, Germany

\begin{abstract}
:
Aim:

The aim of this study was to reveal the role of gender and culture (German vs Polish) in Satisfaction With Singlehood (SWS).

Background:

Due to the number of singles increasing over the past decades, the assessment of the extent to which such people are satisfied with their singlehood and establishment of specific variables enabling satisfaction with life in singlehood to be predicted seem valid. An additional factor was gender and culture, as feminine and masculine roles are defined mainly by familial and matrimonial life and diverse cultural context.

\section{Methods:}

Study 1 encompassed 512 never married childless singles above 30 years old, Study 2: 196 Polish never-married singles, and Study 3: 265 German never-married singles (pairfam data).

Research methods were: Satisfaction with singlehood, Multidimensional Sexuality Questionnaire (MSQ), Inventory of Gender Assessment (IPP), Multidimensional Self-Esteem Inventory (MSEI), UCLA III Loneliness Scale, Romantic Beliefs Scale (RBS), Interpersonal Competences Questionnaire (ICQ), Satisfaction with Life Scale (SWLS). German sample was retrieved from The German Panel Analysis of Intimate Relationships and Family Dynamics - pairfam.

Results:

Study 1 revealed significant medium effects of gender and country, with women and German sample reporting a higher SWS. Study 2 showed different prediction models for Polish sample. SWS was explained by satisfaction with life, romantic belief, loneliness, and competence in women. The predictors in Polish men were: initiating relationships and internal sexual control. Study 3 revealed willingness to have a partner as the only predictor in German women, and in German men: satisfaction with life, loneliness and mating confidence.

\section{Conclusion:}

Satisfaction With Singlehood (SWS) was higher in women than men, regardless of culture. German single never-married women were the most satisfied group. Traditional masculine role predicted higher SWS in single men. Satisfaction with singlehood proved to be separate from satisfaction with life.
\end{abstract}

Keywords: Gender, Singlehood, Satisfaction with relationship status, Satisfaction with singlehood, Self-esteem, Sexuality.

\begin{tabular}{l|l|l|r}
\hline Article History & Received: January 06, 2020 & Revised: February 20, 2020 & Accepted: March 04, 2020
\end{tabular}

\section{INTRODUCTION}

Satisfaction with the present relationship status is examined relatively seldom when compared with satisfaction with life. As far as the relationship status is concerned, scholars

* Address correspondence to this author at the Institute of Psychology, University of Opole, Plac Staszica 1, 45-052 Opole, Poland; Tel: +48 774527370

E-mail: dominika.ochnik@uni.opole.pl make the most frequent references to the term satisfaction with life. Groups differing in the relationship status are compared in terms of their satisfaction with life. Even though such a research approach is valid and constitutes the key element of an individual's functioning, it leads to the emergence of generalizations and does not allow for an in-depth analysis of predictors associated with satisfaction with singlehood to be 
made. This is due to the fact that satisfaction with life constitutes a general cognitive evaluation while satisfaction with the relationship status may serve various roles in shaping satisfaction with life and vice versa [1].

Due to the number of singles increasing over the past decades, the assessment of the extent to which such people are satisfied with their singlehood and establishment of specific variables enabling satisfaction with life in singlehood to be predicted seem valid. The issue is significant and allows for a deeper understanding and improvement of the quality of life of this expanding social group. At the same time, because feminine and masculine roles are defined mainly by familial and matrimonial life $[2,3]$, it seems vital to take the gender aspect into consideration and examine satisfaction with singlehood in women and men.

Despite growth in alternative lifestyles, singles in western countries are still the target of discrimination and prejudice. They also face strong social pressures to obey an "ideology of marriage and family" and to get coupled [4 - 6]. Even though the significance of marriage in Germany is very low, there exists a positive attitude towards having children and perceiving parenthood as a transition to adulthood [7]. On the other hand, the significance of marriage in Poland is higher, and the growth in the number of singles is not as dynamic as it was in previous years [8]. However, due to the stereotypisation and stigmatisation, the social role of never-married, childless singles aged 30 and above, ought to be considered as nontraditional both in Poland and Germany. This may lead to low satisfaction with singlehood.

\subsection{Socio-Cultural Background}

In Northern and Western Europe, the independence index and late marriage are dominant among young adults. Premarital sexuality and cohabitation are relatively more readily accepted in these societies [9]. On the other hand, in East-Central Europe, there is a strong discrepancy between the widely appreciated traditional family values and high divorce rate (and a high number of marriages). At the same time, the acceptance for cohabitation and premarital sexuality is lower than in Northern and Western Europe [9]. In western, industrialized societies, the significance of autonomy and alternative means of achieving life objectives are highlighted. It was observed that marriage is gradually losing its vital role in the transition to adulthood and the development of masculine and feminine identities [10].

Between 2000 and 2018 in Germany, the number of oneperson households increased by $21 \%$ [11].

A positive attitude is expressed towards having children, but not necessarily in the framework of marriage [7]. Poland is also experiencing a rising trend in singlehood. The national census conducted in 2011 recorded approx. 9 million nevermarried women and men in the Polish population [8]. The 2002 census indicated that, when compared with 1988, the number of never-married men increased by $5.4 \%$ and never-married women by $4.6 \%$. Meanwhile, the number of marriages and cohabitation relationships declined [12]. On the other hand, the 2011 census indicated the lack of a significant increase in the number of never-married men and women when compared with 2002 (28.8\% in 2011 vs. $28.5 \%$ in 2002). This denotes that the greatest socio-cultural change emerged towards the end of the $1990 \mathrm{~s}$. The beginning of the $21^{\text {st }}$ century witnessed a halt concerning the rapid growth in the number of never-married men and women.

At the same time, despite the declining significance of marriage, singles feel partly stigmatised $[6,13]$ and face discrimination and stereotypization [14]. They constantly struggle against social pressure $[5,6,15]$ because marriage and permanent relationships are partly perceived as vital elements of development [16]. It was observed that singles themselves perceive other singles in a more negative light than they do couples [14].

\subsection{Satisfaction with Singlehood}

Singlehood constitutes a broad and complex issue which frequently proves problematic for scholars of social sciences [17]. At least 14 categories defining singles may be distinguished in various studies [17]. This means that the social group is diversified, also as far as psycho-social characteristics are concerned. Therefore, making a reference to the relationship status as a sole determinant of wellbeing may be too simplistic. As a consequence, one ought to focus upon the assessment of satisfaction (satisfaction with the relationship status) [18]. Studies indicate that satisfaction with the relationship status (or status satisfaction) constitutes a stronger predictor of general wellbeing than the relationship status per se. People satisfied with their relationship status (single or partnered) manifest a higher satisfaction with life, experience lower distress, regardless of the relationship status itself. The lack of social support proved to predict distress, regardless of the relationship status as well. This means that the lack of social support factors for distress among both the single and partnered.

However, researchers draw attention to the cultural context, which may diversify the significance of the relationship status $[18,19]$ and its impact upon wellbeing. This is due to the fact that culture is of significance for the global satisfaction with life [20, 21]. Studies conducted in the Netherlands, a country offering a variety of lifestyles to women, also indicate a higher percentage of singles satisfied with their lives [22], which may explain a lower significance of the relationship status [18]. The above mentioned studies indicate a significant role of the cultural factor with regard to the feeling of comfort and high quality of life. It may be expected that in liberal cultures, which offer equal opportunities, singles will manifest a higher satisfaction with the relationship status.

Polish studies conducted by Katarzyna Adamczyk [23] indicate that satisfaction with the relationship status is diversified with regard to gender. Women, much like in the Dutch sample [18], proved to be characterized by higher satisfaction with the relationship status. In addition, the previous study also indicates that single women tend to perceive their situation in a more positive light than single men do [24]. The studies proved that satisfaction with the relationship status is a stronger predictor of satisfaction with life, emotional wellbeing, psychological wellbeing, and 
depressive symptoms than the relationship status itself $[25,26]$. At the same time, differences between singles and the partnered were observed. Singles were less satisfied with their relationship status. Therefore, they experience anxiety and stress, which manifests in functioning disorders and symptoms of depression. Longitudinal studies revealed that satisfaction with the relationship status predicts satisfaction with life in the second stage of the study, but only in case of emotional and psychological wellbeing and depressive symptoms [25]. Further studies by Adamczyk [26] revealed a full mediation of the relationship between relationship status and wellbeing via satisfaction with the relationship status and fear of being single. Such results explain the level of wellbeing via an individual's subjective perception of their relationship status rather than via the relationship status per se.

German studies on representative samples highlight the possession of children in comparison with the childless [27]. Childless women are more satisfied with their leisure time but are characterized by lower satisfaction with life. The positive impact of parenthood is associated with economic status. Poor parents did not differ from the childless with regard to their satisfaction with life. However, those with average and high incomes were characterized by higher satisfaction with life. The relationship between parenthood and satisfaction with life is considered a cause-effect relationship because studies in the matter were longitudinal in character. It ought to be noted that the present results of the own study pertain to childless adults. Therefore, these may explain a lower satisfaction with the status or satisfaction with life among childless singles. Having and rearing children is also perceived in a different way by singles and partnered. The analysis by Gal Slonim and Astrid Schütz [28] revealed that singles by choice perceive childrearing as more expensive, limiting one's freedom and putting parents under a nervous strain when compared with singles by chance and with the partnered.

It ought to be noted that researchers devote little attention to the diversity of singles with regard to gender. However, gender was observed to determine several aspects of the psycho-social functioning of singles [1]. As far as results pertaining to the population are concerned, never-married single women feel more physically (sexually) attractive than single men [29]. On the other hand, as far as sexuality is concerned, women and men score similar to other social groups. Single men score higher in sexual preoccupation, sexual motivation, external sexual control, sexual anxiety, and monitoring sexual sensations than single women [30]. Singles may be perceived as sexually inactive or being active in a way which, except for a long-term relationship, may be socially unacceptable. These two aspects are the reason behind the anxiety and sexual monitoring among men. Among men, high sexual self-esteem is associated with fulfilling the stereotypical model of masculinity. Among women, it is associated with the non-stereotypical model being pursued [30].

\subsection{Objectives}

The first objective of the current study was to assess the extent to which singles are satisfied with their relationship status, especially in Germany and Poland countries with two distinct cultures and sociological structures. The second target was to understand whether there exist any gender differences which seem vital because feminine and masculine roles are defined mainly by familial and matrimonial life [2, 3]. Finally, we pursued the examination of psychological predictors of satisfaction with singlehood among Polish and German childless never-married single women and men.

\subsection{Hypotheses}

Based upon the review of the literature, the following hypotheses were posed:

H1. Satisfaction with singlehood differs with regard to gender among Polish and German singles. Due to women's higher satisfaction with the relationship status, it was expected that they would manifest higher satisfaction with singlehood than men (Study 1).

H2. Satisfaction with singlehood differs with regard to the country of origin. Due to a lower significance of marriage in Germany, higher satisfaction with singlehood was expected among German singles when compared with the Polish sample (Study 1).

H3. Dimensions of sexuality, gender, self-esteem dimensions, the feeling of loneliness, romantic beliefs, interpersonal competences, and satisfaction with life constitute the predictors of satisfaction with singlehood for Polish singles. Models of prediction differ in single childless never-married men and women (Study 2).

H4. Interest in becoming partnered, satisfaction with life, loneliness, sexual activity, and mating confidence constitute the predictors of satisfaction with singlehood for German singles. Models of prediction differ in single childless nevermarried men and women (Study 3).

\section{METHODS}

\subsection{Measurements}

(1) Satisfaction with singlehood [1]. Respondents assessed the satisfaction by means of a 1-5 scale (1- extremely low, 5extremely high, satisfaction with singlehood in temporal perspective).

(2) Multidimensional Sexuality Questionnaire (MSQ) [31] assessing sexuality in 12 dimensions, Polish adaptation. The MSQ in Polish adaptation [1] is composed of 60 statements. Respondents were required to express their attitude towards the statements by means of a 5 -point scale. The response was to determine the extent the statements pertained to respondents' personal experiences with regard to sexual relations. Sexuality dimensions are associated with sexual self-esteem $(a=0.91)$, sexual preoccupation $(a=0.78)$, internal sexual control $(a=0.66)$ and external sexual control $(a=0.63)$, sexual consciousness $(a=$ $0.71)$, sexual motivation $(a=0,81)$, sexual anxiety $(a=0,87)$, sexual assertiveness $(a=0.44)$, sexual depression $(a=0.88)$, sexual monitoring $(a=0,77)$, fear of sex $(a=0.75)$, and sexual satisfaction $(a=0.88)$. Due to the low reliability of the sexual assertiveness scale, this scale was excluded from further statistical analyses. The scale of internal and external sexual control should be treated with particular caution due to the 
slightly lower than desired Cronbach's a reliability index (0.7). Other scales were characterized by high reliability and theoretical accuracy analyses [1]. This indicates high psychometric properties of the tool which allows the use of the Multidimensional Sexuality Questionnaire in psychological research. The dimensions of sexuality are significantly related to the history of sexual life, sexual activity and attitudes towards sexual life [31].

(3) Inventory of Gender Assessment (IPP) [32]. The inventory was adapted and developed on the basis of the American Bem Sex Roles Inventory BSRI. The theoretical basis for the inventory was supplied by the gender schema theory by L. S. Bem (1981). The IPP assesses the intensity of masculinity and femininity. The inventory is composed of 35 features assessed on a 5-point scale. The Kuder-Richardson formula in the Ferguson adaptation was used in order to determine the reliability of the test. The following reliability coefficients were obtained: for the Masculinity scale 0.78 , for the Femininity scale 0.79 .

(4) Multidimensional Self-Esteem Inventory (MSEI) [33]. The inventory constitutes a self-assessment tool enabling various aspects of self-esteem to be examined (11 scales). It was based upon the self-knowledge and self-esteem model by Esptein [34]. The tool is composed of 116 statements. Respondents were to express their attitude towards these by means of a 5-point scale. MSEI gained satisfactory or high internal consistency of most scales (Cronbach's a 0.70-0.90) and high stability (correlations between two measurements taken with an interval of 2 weeks were between 0.73 and 0.96 ).

(5) UCLA III Loneliness Scale [35] in the Polish adaptation [1]. The multidimensional scale measures respondents' emotional reactions to the perceived discrepancy between the pursued and achieved level of social contacts (a $=0.95$ ).

(6) Romantic Beliefs Scale [36]. It is a tool assessing the level of romantic beliefs reflecting the ideology of romanticism [36]. The tool is composed of 15 items. Respondents express their attitude towards these using a 7-point scale. In its original version, the scale scored Cronbach's alpha of 0.81 . The reliability of the subscales ranges from 0.57 to 0.80 . The adaptation of the Romantic Beliefs Scale [1] indicates the reliability of the scales by the following Cronbach's a: global romantic beliefs $(a=0.81)$, Love finds a way $(a=0.79)$, One and only $(a=0.61)$, Idealization $(a=0.79)$, Love at first sight $(a=0.57)$.

(7) Interpersonal Competences Questionnaire (ICQ) [37] as adapted by Ochnik [1]. It examines interpersonal competences as a multidimensional phenomenon. The tool is composed of 40 statements describing a hypothetical situation. Respondents express their attitude towards these by means of a 5-point scale. The original version of the scale proved reliable by scoring 0.77-0.87 Cronbach's a. The reliability of the Polish version of the tool was also high and scored the following Cronbach's a: Initiating relationships $(a=0.90)$, Asserting displeasure with others $(a=0.89)$; Disclosing personal information $(\mathrm{a}=0.84)$; Managing interpersonal conflict ( $a=0.82$ ); Providing emotional support and advice $(a=0.90)$.
(8) Satisfaction with Life Scale SWLS [38] in the Polish adaptation. The scale consists of five statements. Respondents expressed the extent each of these pertained to their lives by means of a 7-point scale. The assessment measures global satisfaction with life emerging from the comparison of their situation with standards set by oneself. The Polish adaptation scored satisfactory values $(a=0.81)$ similar to the original version [39].

(9) The German Panel Analysis of Intimate Relationships and Family Dynamics - pairfam:

- Satisfaction with singlehood (single item, 10-point scale, unified to a 5-point scale).

- Willingness to have a partner.

- Satisfaction with life (shortened SWLS).

- Feeling of loneliness (shortened UCLA).

- Self-esteem (shortened SES).

- Frequency of sexual activity.

- Mating Confidence - Subjective Chances in the Partner Market.

All tools are single-item scales.

\subsection{Respondents and the Course of the Study}

The definition of the term single encompasses is the source of controversy [ 17 ]. For the purpose of the present study, it was agreed that singles will be represented by people of 30 years of age onwards, having no children and never married. It is, therefore, a group which does not meet social requirements as regards starting a family, having children and disregarding the social clock. In Poland, the mean age of the first marriage for women is 28 years old and 29,8 for men, whereas in Germany -31 years for women and 33,8 for men [40]. Such features allow for the essence of being single to be revealed. Therefore, based upon the review of the literature [17], the definition of a single which takes the following criteria into consideration was established:

- Childless, without a partner (no long-term, at least 6 months' relationship).

- $\quad$ Aged above 30 .

- Never married.

- Heterosexual.

Those inclusive criteria for participants were applied in Study 1, Study 2 and Study 3.

Study 1 encompassed 512 respondents. The study pertained to the significance of discrepancies concerning satisfaction with singlehood with regard to gender in Poland and Germany. The structure of the sample was the following: 196 Polish singles (123 women and 73 men, $M_{\text {age }}=34$ ) and 316 German respondents (103 women and 213 men, $M_{\text {age }}=37$ ). This study analysed the satisfaction with singlehood with regard to gender and country of origin.

The data retrieved from the Polish sample was used in Study 1 (satisfaction with singlehood) and Study 2 (model of satisfaction with singlehood predictors). Therefore, in Study 2, the same Polish sample but different variables were used. The 
Polish sample was surveyed by means of the paper-pencil method and online. Sampling was purposive. Respondents were notified of the research character of the study aims to develop a full characteristic of singles and of the anonymity of their responses. These were critical due to the fact that the tool discussed several psychological dimensions, including sexuality. The online survey was conducted in cooperation with the Sympatia dating portal, which encouraged its users to complete the questionnaires twice. An additional way of collecting data was direct contact with the singles' community in the form of lectures and the co-organization of meetings for singles. As a result of these activities, 1, 971 people took up filling in the questionnaires online, 327 of whom fully completed the forms. Out of this group, only 186 people met the aforementioned research criteria. The average time to complete the online questionnaire was 70 minutes $44 \mathrm{~s}$. In total, as a result of the research conducted online and via the paperpencil method, 196 questionnaires were obtained, fully completed by persons meeting the research criteria. The selected criteria featured in the study (childlessness and nevermarried after 30) hindered access to the group of potential study participants. The toolkit was provided in the Polish language version.

The average age of the respondents was 36 years. On average, women were $35(\mathrm{SD}=6.24)$ and men $34(\mathrm{SD}=4.84)$. $89 \%$ of single women and $92 \%$ of single men were between 30 and 40 years of age. Nearly half of the respondents (47\%) lived with a family, and $43 \%$ in one-person households. Only $9 \%$ of the respondents lived with unrelated persons. $1 \%$ of the respondents marked their answer: Others. Nearly half of the respondents declared more than one long-term relationship (over a 6 month period) (47\%), and the remaining persons declared only one relationship (26\%) or no relationship (27\%). Most of the participants were single for more than 5 years (36\%), every fifth person from 2 to 5 years $(22 \%), 14 \%$ from 1 to 2 years, $13 \%$ from 6 months to 1 year, and $15 \%$ were single for less than half a year. Women's average results reflected those of men in all examined dimensions of self-esteem except for the scale of physical attractiveness. Men achieved low scores on the scale of physical (sexual) attractiveness. There were no significant differences in femininity and masculinity among single women and men. Among single women, there were: $43 \%$ feminine (high femininity, low masculinity), $35 \%$ androgynous (high femininity, high masculinity), 14\% masculine (low femininity, high masculinity) and $8 \%$ undifferentiated (low femininity, low masculinity). Among single men: $15 \%$ masculine (low femininity, high masculinity), $32 \%$ androgynous (high femininity, high masculinity), $32 \%$ feminine (high femininity, low masculinity) and $21 \%$ of undifferentiated (low femininity, low masculinity).

In Study 1, the German sample (103 women and 213 men, $M_{\text {age }}=37$ ) was recruited from the fifth wave of the German Panel Analysis of Intimate Relationships and Family Dynamics - pairfam, based upon the above criteria [41]. Pairfam is a multi-disciplinary, longitudinal study for researching partnership and family dynamics in Germany. The annually collected survey data from a nationwide random sample of more than 12,000 persons representing the following three birth cohorts 1971-73, 1981-83, 1991-93 and their partners, parents and children offers unique opportunities for the analysis of partner and generational relationships as they develop over the course of multiple life phases. The pairfam panel sampling is obtained by means of the CASI method. The questionnaires are provided in the German language version.

Study 2 analysed the predictors of satisfaction with singlehood among the Polish sample of singles from Study 1 but with various and advanced variables: dimensions of sexuality and self-esteem, romantic beliefs, loneliness, interpersonal competences, and satisfaction with life. It also scrutinized variables related to singlehood as: number of previous relationships, singlehood by choice, or interest in entering a relationship or marriage.

Study 3 employed the results of the German sample $(\mathrm{N}=$ 265) from the seventh wave of the German Panel Analysis of Intimate Relationships and Family Dynamics - pairfam [41]. Inclusive criteria were met by 70 single women and 195 single men $\left(M_{\text {age }}=37\right)$. Study 3 showed the predictors of satisfaction with singlehood in the German sample. The introduced variables from the research panel corresponded with the Polish research: willingness to have a partner (single by choice), selfesteem, feeling of loneliness, satisfaction with life, frequency of sexual activity, mating confidence - corresponding to physical attractiveness. It should be noted that this is a severe limitation of this paper as the variables are not exactly the same. Nevertheless, they were not directly compared in one model but allowed to reveal the psychological predictors of satisfaction with singlehood.

\section{RESULTS}

SPSS 24 software was applied in the statistical analysis.

Study 1 verified hypotheses $\mathrm{H} 1$ and $\mathrm{H} 2$. These were fully confirmed. The Polish sample reported low to moderate levels of satisfaction with singlehood (on a scale from 1 to $5 ; 35 \%$ gave a response of " 3 " and $25 \%$ a response of " 2 "). The German sample reported moderate to high levels of satisfaction with singlehood (on a scale from 1 to $5 ; 32 \%$ of participants gave the highest response " 5 " to the question).

The study revealed significant differences concerning satisfaction with singlehood in never-married singles with regard to gender and country. A two-way ANOVA analysis (gender x country) revealed that the differences in satisfaction with singlehood between the two countries are significant, $F(1.499)=77.96, p<.001, \eta^{2}=0.14$. Both Polish single childless never-married men $(\mathrm{M}=2.44, \mathrm{SD}=1.05)$ compared to Polish single women $(\mathrm{M}=2.84, \mathrm{SD}=1.16)$ and German single men $(\mathrm{M}=3.48, \mathrm{SD}=1.27)$ compared to German single women $(\mathrm{M}=3.84, \mathrm{SD}=1.25)$ reported a significantly lower degree of satisfaction with being single. Moreover, Polish singles reported lower satisfaction with singlehood compared to German singles (Fig. 1). 


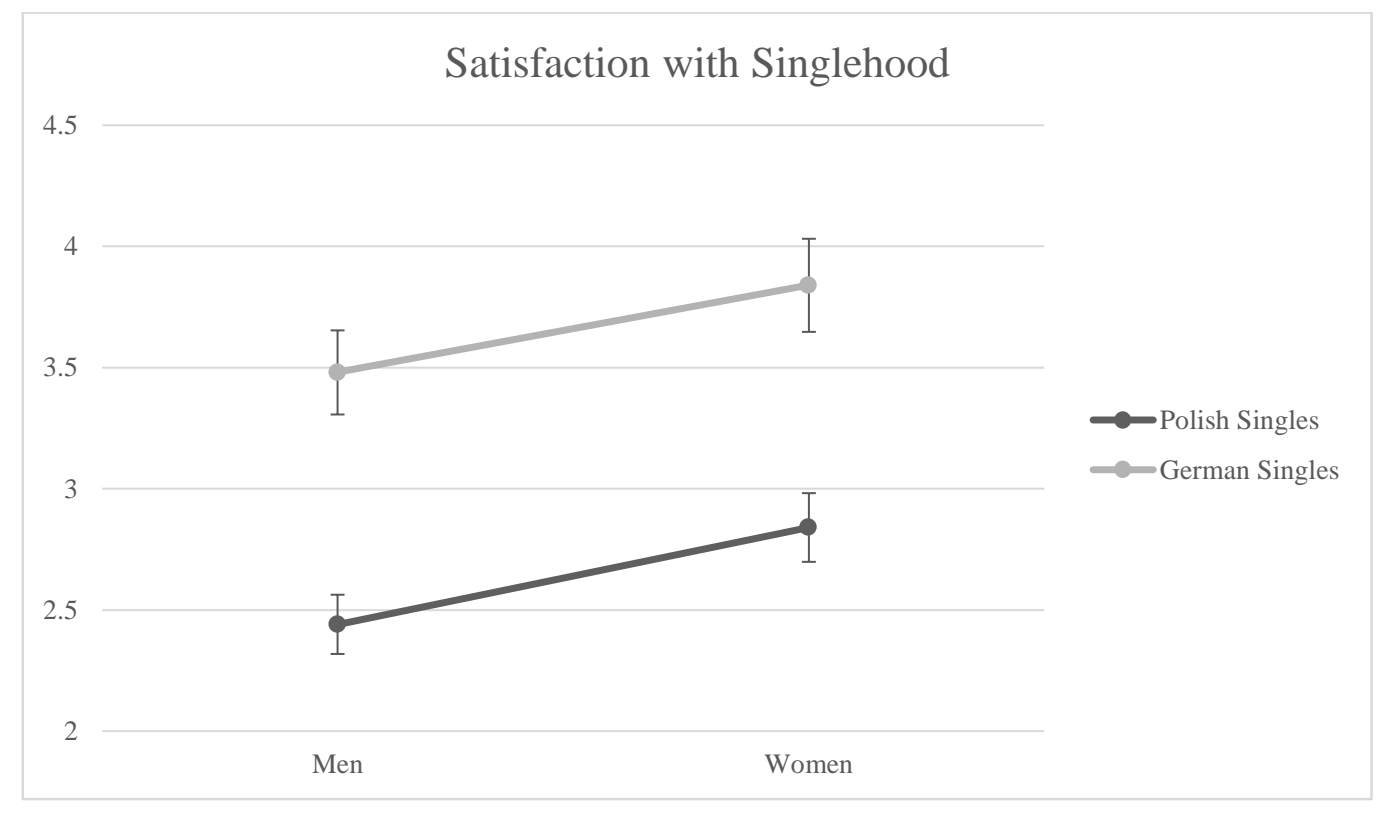

Fig. (1). Means of Satisfaction with Singlehood in German and Polish single men and women.

\subsection{Predictors of Satisfaction with Singlehood in Polish Never-Married Single Women and Men (Study 2)}

In order to develop the model for predicting satisfaction with singlehood among women and men, a linear regression analysis was conducted. Due to an extensive number of variables, a stepwise method was applied. The method enables variables significant for the prediction model to be isolated. It also excludes co-linearity, i.e. rejects strongly correlated variables.

The psycho-social functioning variables were introduced into the satisfaction with singlehood prediction model. The variables significantly diversified and correlated with satisfaction with singlehood:

- Number of previous relationships, singlehood by choice, interest in entering a relationship or marriage.

- Satisfaction with life.

- Feeling of loneliness.

- Self-esteem dimension.

- Interpersonal competences.

- Psychological masculinity.

- Dimensions of sexuality.

- Romantic belief concerning the existence of the one and only partner and love at first sight.

The linear regression analysis revealed a significant prediction model among single women in four steps. The regression model proved significant. High satisfaction with life, low romantic belief concerning the one and only partner, low feeling of loneliness and high self-esteem regarding leadership skills (feeling of being an authority) predicted high satisfaction with singlehood among Polish women. The surveyed predictors explained a total of $43 \%$ of the dependent variable. Those predictors exclusively turned out to be significant for satisfaction with singlehood in Polish women.
The linear regression analysis revealed a significant prediction model among single men in two steps. The regression model proved significant. High interpersonal competences in initiating contacts and the feeling of internal sexual control enabled high satisfaction with singlehood to be predicted among Polish men. The remaining introduced variables turned out to be insignificant. The surveyed predictors factor for a total of $18 \%$ of the dependent variable (Table 1).

\subsection{Predictors of Satisfaction with Singlehood in German Never-Married Single Women and Men (Study 3)}

Among the variables offered by pairfam panel, the variables corresponding to those in the Polish Study 2 were used. The following psycho-social functioning variables were incorporated into the German model for the prediction of the satisfaction with singlehood:

- Willingness to have a partner.

- Satisfaction with life (simplified SWLS).

- Feeling of loneliness (simplified UCLA).

- Self-esteem (simplified RSES).

- Frequency of sexual activity.

- Mating Confidence - Subjective Chances in the Partner Market.

The linear regression analysis revealed a significant prediction model for women in one step. The regression model was significant. Low interest in becoming partnered factored for high satisfaction with the relationship status in 35\% of the dependent variable. Satisfaction with life, feeling of loneliness, self-esteem, frequency of sexual activity and mating confidence - have been excluded and turned out to be insignificant predictors.

The linear regression analysis revealed a significant 
prediction model for men in four steps. The regression model proved significant. High interest in becoming partnered, high satisfaction with life, low feeling of loneliness and high mating confidence were strong predictors of high satisfaction with singlehood among German men and factored for a total of $18 \%$ of the dependent variable. Self-esteem, frequency of sexual activity turned out to be insignificant predictors of satisfaction with singlehood (Table 2).

\section{DISCUSSION}

Study 1 revealed significant differences concerning satisfaction with singlehood in never-married singles concerning gender and country. Women, in general, had higher satisfaction with singlehood compared to single men. In addition, the German sample had higher satisfaction with singlehood compared to the Polish sample. German never-married single women were the most satisfied with singlehood group compared to Polish women as well as German and Polish single men. Study 2 verified hypothesis H3 and Study 3: H4. These were partly confirmed. Due to the fact that data for German and Polish samples were collected in two separate studies (pairfam panel pertains solely to the German population), certain variables differ. As a consequence, the models of prediction in the Polish and German samples have certain limitations.

Models concerning the prediction of satisfaction with singlehood in Polish never-married singles with regard to gender turned out to be distinctive. It ought to be noted that variables associated with being single such as singlehood by choice, interest in entering marriage/ relationship, and the number of previous long-term relationships, did not prove to be significant predictors both for women and men. Satisfaction with life did not significantly predict satisfaction with singlehood. This denotes that, for Polish single men, the relationship status refers to the present situation. For Polish single women, it is developed on the basis of general satisfaction with life. Satisfaction with the relationship status among Polish single women was determined by low romantic beliefs concerning the existence of the one and only partner. Therefore, lower romantic beliefs enhanced satisfaction with singlehood. Despite a higher global intensity of romantic beliefs among men [36, 42], the aspect is more vital for women as far as singlehood is concerned. The feeling of being an authority for others, which is associated with acceptance and strong social position in a group, constituted an additional significant element. As a consequence, single women who have a network of contacts and who develop their position in a group felt more satisfied with their relationship status. This means that they were able to shape their satisfaction on the basis of other relations, non-romantic in character, which is also associated with obtaining social support. Therefore, Polish single women developed their satisfaction with the relationship status on the basis of extensive psychological dimensions, general satisfaction with life, low feeling of loneliness, limited romantic beliefs, and social position in the group.

Table 1. Stepwise linear regression analysis of men's and women's satisfaction with singlehood- Polish sample (Study 2 ).

\begin{tabular}{|c|c|c|c|c|c|c|}
\hline \multirow[t]{2}{*}{ Variable } & \multicolumn{3}{|c|}{$\begin{array}{l}\text { Women } \\
N=123\end{array}$} & \multicolumn{3}{|c|}{$\begin{array}{c}\text { Men } \\
N=73\end{array}$} \\
\hline & $\boldsymbol{\beta}$ & $t$ & $p$ & $\beta$ & $t$ & $p$ \\
\hline Satisfaction with life & 0.32 & 3.19 & 0.002 & & & \\
\hline Romantic belief: One and only & -0.27 & -3.70 & $<0.001$ & & & \\
\hline Loneliness & -0.21 & -2.23 & 0.028 & & & \\
\hline Self-esteem: Competence & 0.17 & 2.15 & 0.030 & & & \\
\hline Interpersonal competences - Initiating relationships & & & & 0.30 & 2.68 & 0.009 \\
\hline Internal Sexual Control & & & & 0.26 & 2.39 & 0.020 \\
\hline$F$ & \multicolumn{2}{|c|}{22.88} & $<0.001$ & \multicolumn{2}{|c|}{8.33} & $<0.001$ \\
\hline$R^{2}$ & \multicolumn{2}{|c|}{0.43} & & \multicolumn{2}{|c|}{0.18} & \\
\hline
\end{tabular}

Dependent variable: Satisfaction with Singlehood

Table 2. Stepwise linear regression analysis of men's and women's satisfaction with singlehood- German sample (Study 3).

\begin{tabular}{|c|c|c|c|c|c|c|}
\hline \multirow[t]{2}{*}{ Variable } & \multicolumn{3}{|c|}{$\begin{array}{c}\text { Women } \\
N=70\end{array}$} & \multicolumn{3}{|c|}{$\begin{array}{c}\text { Men } \\
N=195\end{array}$} \\
\hline & $\boldsymbol{\beta}$ & $t$ & $p$ & $\boldsymbol{\beta}$ & $t$ & $p$ \\
\hline Willingness to have a partner & -0.50 & -4.68 & $<0.001$ & -0.38 & -6.79 & $<0.001$ \\
\hline Satisfaction with life & & & & 0.25 & 3.92 & $<0.001$ \\
\hline Loneliness & & & & -0.19 & -2.39 & 0.004 \\
\hline Mating confidence- Subjective Chances in the Partner Market & & & & 0.18 & 2.97 & 0.003 \\
\hline$F$ & \multicolumn{2}{|c|}{7.23} & $<0.001$ & \multicolumn{2}{|c|}{27.55} & $<0.001$ \\
\hline$R^{2}$ & \multicolumn{2}{|c|}{0.35} & & \multicolumn{2}{|c|}{0.45} & \\
\hline
\end{tabular}

Dependent variable: Satisfaction with Singlehood 
On the other hand, only two predictors were isolated for men. These factored for satisfaction with the status to a much lower degree than variables in the group of women (18\%). Therefore, one ought to seek other predictors which would offer a better understanding of factors determining satisfaction with singlehood among Polish singles. For single men, the competence of establishing contacts, thus initiating relationships, in accordance with the stereotypical masculine role, proved critical. The feeling of internal sexual control was an additional predictor. This feature denotes that sexual aspects of an individual's life are determined by their personal control [31]. However, single men were more satisfied with their status when they successfully initiated new relations and controlled their sexual lives, thus fulfilling the traditional masculine role associated with sexual activity [43]. The lack of active sexual life was more frustrating for men than women [44]. However, it ought to be noted that sexual activity was not analysed among Polish singles. The study examined the feeling of sexual control, which may constitute a subjective assessment of one's expectations towards the realization of one's objectives in the sexual aspect. These results can be interpreted from the perspective of the Gender Role Conflict Theory [45] resulting from the lack of congruence between individual characteristics and social expectations. High masculinity constitutes an example of the application of this theory. It hinders the disclosure of emotions. However, a different relationship can be observed for single men. Given the high psychological femininity of Polish single men, they may experience a sense of lack of fulfilling the social gender role. Therefore, despite the high intensity of femininity and androgyny, satisfaction with singlehood among men is reinforced by the realization of the traditional masculine role. This means that regardless of the type of psychological gender, men had higher satisfaction with singlehood when fulfilling the traditional gender norm.

In the German sample, the models of satisfaction with singlehood turned out to be different in never-married single women and men. Among the selected predictors, merely the frequency of sexual activity did not predict satisfaction with the status among German single men and women. When comparing these results with those of Polish single men, it ought to be noted that it is not sexual activity, but the subjective feeling of control over this sphere of life which enables satisfaction with singlehood to be predicted. Predictors of the German group proved to differ when compared with the Polish sample. As far as German single women are concerned, satisfaction with the status is determined by their willingness to have a partner. This specific factor explained $35 \%$ of the variable. This means that German single women are satisfied with singlehood if they do not seek partners. The remaining psychological variables bear no significance. Such a result may be interpreted as the lack of limitations in the strong feeling of control regarding decision-making. On the other hand, the satisfaction of German single men was similar to the one manifested by Polish single women. For the German male group, satisfaction with life and loneliness were predictors. The subjective assessment of one's chances on the dating market, which is associated with confidence in dating, was an additional predictor for German single men. These results are similar to those achieved by Polish single men whose contact initiation competencies enabled the satisfaction with the status to be predicted. Therefore, these are associated with the realization of the traditional masculine role.

The size of the sample is undoubtedly one of the limitations of the study. It ought to be noted that the whole sample is characterized by strict inclusion criteria. Therefore, the results of singles who have children or those aged below 30 may indicate different predictors.

\section{CONCLUSION}

This was the first study comparing the satisfaction with singlehood in never-married single adults with regard to gender and culture (Polish vs. German). Higher satisfaction with the relationship status among single women than single men, both in German and Polish samples, was revealed. On the other hand, higher satisfaction with the status among German singles may be explained by the higher global satisfaction with life in the society [46], and less significance being attached to marital norms in this country, which may manifest in a greater social tolerance for non-traditional lifestyles.

Although the conclusions are limited by the study design, it can be noted that the prediction model in German single men turned out to be more similar to Polish single women. Both models pointed to several psychological factors locating satisfaction with the singlehood in a broader perspective.

Furthermore, satisfaction with singlehood among Polish and German single men was explained by the realization of the traditional masculine role (especially in the Polish sample). It ought to be noted that from this perspective, it is rather the single men's group who live in a traditional social context relating to their sexuality than single women, who were less restricted by social, traditional norms. German single women seemed to be the least constrained by social and relational expectations and to build their satisfaction with singlehood based only based on the willingness to have a partner.

As a consequence, the study revealed discrepancies with regard to gender and country of origin in satisfaction with singlehood prediction model. Therefore, the results may play a role in diminishing the process of singlism and thus the feeling of stigmatisation among single people [13]. It showed satisfaction with singlehood as a phenomenon built partially in response to social expectations and cultural norms. Hence, in analysing the wellbeing of singles, the cultural context should be taken into consideration for improved understanding.

Satisfaction with singlehood proved to be separate from satisfaction with life. This justifies the validity of examining singlehood as a distinct phenomenon. The present study encourages further exploration of the psychological functioning of singles as a specific and independent issue, instead of merely viewing it as a shortage and incompleteness.

\section{ETHICS APPROVAL AND CONSENT TO PARTI- CIPATE}

The study was approved by the Katowice Business University Institutional Review Board, Katowice, Poland. 


\section{HUMAN AND ANIMAL RIGHTS}

No animals/humans were used for studies that are the basis of this research.

\section{CONSENT FOR PUBLICATION}

Informed consent was obtained from all the participants when they were enrolled.

\section{AVAILABILITY OF DATA AND MATERIALS}

The data supporting the findings for the Polish sample is available in the Department of Psychology, University of Opole. The corresponding author of the present work is available for any information about the data. The German sample was retrieved from the German Panel Analysis of Intimate Relationships and Family Dynamics - pairfam (https://www.pairfam.de/daten/).

\section{FUNDING}

None.

\section{CONFLICT OF INTEREST}

The authors declare no conflict of interest, financial or otherwise

\section{ACKNOWLEDGEMENTS}

Declared none.

\section{REFERENCES}

[1] Ochnik D. Singlehood - psychosocial consequences of being single in men and women. Ph.D. diss., Dept. of Psychology, University of Silesia 2016. Retrieved from http://www.sbc.org.pl/publication $/ 246942$

[2] Wood W, Eagly AH. Biosocial construction of sex differences and similarities in behavior.Advances in experimental social psychology 2012; pp. 55-123.

[http://dx.doi.org/10.1016/B978-0-12-394281-4.00002-7]

[3] Mandal E. Podmiotowe i interpersonalne konsekwencje stereotypów związanych z płcią.[Subjective and interpersonal consequences of the stereotypes related to gender]. 2nd ed. Katowice: University of Silesia Press 2004.

[4] DePaulo BM, Morris WL. Singles in society and in science. Psychol Inq $2005 ; 16: 57-83$.

[http://dx.doi.org/10.1207/s15327965pli162\&3_01]

[5] Morris WL, DePaulo BM, Hertel J, Taylor LC. Singlism - Another problem that has no name: Prejudice, stereotypes, and discrimination against singles.Morrison, MA: Ed. The Psychology of Modern Prejudice 2008; pp. 165-94.

[6] Slonim G, Gur-Yaish N, Katz R. By choice or by circumstance? Stereotypes of and feelings about single people. Stud Psychol (Bratisl) 2015; 57: 35-48.

[http://dx.doi.org/10.21909/sp.2015.01.672]

[7] Klärner A. The low importance of marriage in eastern Germany social norms and the role of peoples' perceptions of the past. Demogr Res 2015; 33: 239-72.

[http://dx.doi.org/10.4054/DemRes.2015.33.9]

[8] GUS National Census 2012 Retrieved from www.stat.gov.pl

[9] Therborn G. Between Sex and Power: Family in the World 1900-2000. New York: Routledge 2004

[http://dx.doi.org/10.4324/9780203643297]

[10] Thornton A, Axinn WG, Xie Y. Marriage and cohabitation. Chicago: The University of Chicago Press 2007. [http://dx.doi.org/10.7208/chicago/9780226798684.001.0001]

[11] Statista, Number of households in Germany from 2000 to 2018, by size. 2019. Retrieved from https://www.statista.com/statistics/464187 /households-by-size-germany/

[12] GUS. National Census 2003. Retrieved from www.stat.gov.pl
[13] Ochnik D, Mandal E. Do Polish never-married singles feel stigmatized?Singlehood from Individual and Social Perspective. 2016; pp. $212-47$

[14] Hertel J, Schütz A, DePaulo BM, Morris WL, Stucke TS. She's single, so what? How are singles perceived compared with people who are married? Z Famforsch 2007; 2: 139-58.

[15] DePaulo BM, Morris WL. The unrecognized stereotyping and discrimination against singles. Curr Dir Psychol Sci 2006; 15: 251-4. [http://dx.doi.org/10.1111/j.1467-8721.2006.00446.x]

[16] Morris WL, Sinclair S, DePaulo BM. No shelter for singles: The perceived legitimacy of marital status discrimination. Group Process Intergroup Relat 2007; 10: 457-70.

[http://dx.doi.org/10.1177/1368430207081535]

[17] Ochnik D. The conceptual and definition problems of the 'single' notion in the social science. Stud Psychol 2012; 50: 63-74.

[18] Lehmann V, Tuinman MA, Braeken J, Vingerhoets AJJM, Sanderman R, Hagedoorn M. Satisfaction with relationship status: Development of a new scale and the role in predicting well-being. J Happiness Stud 2015; 16: 169-84.

[19] Gubernskaya Z. Changing attitudes toward marriage and children in six countries. Sociol Perspect 2010; 53: 179-200. [http://dx.doi.org/10.1525/sop.2010.53.2.179]

[20] Zullig KJ, Huebner SE, Pun SM. Demographic correlates of domainbased life satisfaction reports of college students. J Happiness Stud 2007; 10: 229-138.

[http://dx.doi.org/10.1007/s10902-007-9077-y]

[21] Veenhoven R. The study of life satisfaction. In: A comparative study of satisfaction with life in Europe. 1996; pp. 11-48.

[22] De Vries HH, van Dijck HML, Kuiper NY. Social participation of singles SWOKA, Report 143 Haag. Leiden: Sinteur 1994.

[23] Adamczyk K. Development and validation of a Polish-language version of the Satisfaction with Relationship Status Scale (ReSta). Curr Psychol 2017; 38: 8-20.

[http://dx.doi.org/10.1007/s12144-017-9585-9]

[24] Jong-Giervield J, de Aalberts M. Singlehood. A creative or a lonely experience? J Fam Econ Issues 1980; 3: 350-68.

[25] Adamczyk K. Going beyond relationship status: A cross-sectional and longitudinal investigation of the role of satisfaction with relationship status in predicting Polish young adults' mental health. J Soc Clin Psychol 2017; 36: 196-215.

[http://dx.doi.org/10.1521/jscp.2017.36.4.265]

[26] Adamczyk K. Direct and indirect effects of relationship status through satisfaction with relationship status and fear of being single on Polish young adults' well-being. Pers Individ Dif 2017; 111: 51-7. [http://dx.doi.org/10.1016/j.paid.2017.01.056]

[27] Pollmann-Schult M. Parenthood and life satisfaction: Why Don't children make people happy? J Marriage Fam 2014; 76: 319-36. [http://dx.doi.org/10.1111/jomf.12095]

[28] Slonim G, Schütz A. Singles by circumstance hold similar perceptions of the costs and benefits of romantic relationships as coupled individuals but differ from singles by choice. 27 th annual convention of the Association for Psychological Science (APS).

[29] Ochnik D, Mandal E. Do single women feel more physically attractive than single men? Body appearance self-esteem predictors in nevermarried single men and women. Abstracts Supplement: Appearance Matters 7. Body Image 2016; 18: I.

[30] Ochnik D. Sexuality in single women and men. In: Women, men and close relationships. 2017; pp. 187-203.

[31] Snell WE. New directions in the psychology of human sexuality: research and theory. Cape Girardeau, MO: Snell Publications 2001

[32] Kuczyńska A. Inventory of Psychological Gender Assessment Manual. 1992.

[33] O'Brien EJ, Epstein S. The Multidimensional Self-Esteem Inventory (MSEI): Professional manual. Odessa, FL: Psychological Assessment Resources 1988.

[34] Epstein S. The self-concept: A review and the proposal of an integrated theory of personality.Personality: Basic issues and current research. 1980; pp. 82-132.

[35] Russell DW. UCLA Loneliness Scale (Version 3): Reliability, validity, and factor structure. J Pers Assess 1996; 66(1): 20-40. [http://dx.doi.org/10.1207/s15327752jpa6601_2] [PMID: 8576833]

[36] Sprecher S, Metts S. Development of the 'Romantic Scale' and the examination of the effects of gender and gender-role orientation. J Soc Pers Relat 1989; 6: 387-411. [http://dx.doi.org/10.1177/0265407589064001]

[37] Buhrmester D, Furman W, Wittenberg MT, Reis HT. Five domains of interpersonal competence in peer relationships. J Pers Soc Psychol 
1988; 55(6): 991-1008

[http://dx.doi.org/10.1037/0022-3514.55.6.991] [PMID: 3216292]

[38] Diener E, Emmons RA, Larsen RJ, Griffin S. The satisfaction with life scale. J Pers Assess 1985; 49(1): 71-5.

[http://dx.doi.org/10.1207/s15327752jpa4901 13] [PMID: 16367493]

[39] Juczyński Z. Measurement instruments in the promotion and psychology of health. Warsaw: Pracownia Testów Psychologicznych PTP 2009.

[40] OECD. OECD Family Database. SF3.1: Marriage and divorce rates 2019, retrieved from: http://www.oecd.org/els/family/database.html

[41] Huinink J, Brüderl J, Nauck B, Walper S, Castiglioni L, Feldhaus M. Panel analysis of intimate relationships and family dynamics (pairfam): Conceptual framework and design. Z Famforsch 2011; 23:
[42] Weaver SE, Ganong LH. The Factor Structure of the Romantic Beliefs Scale for African Americans and European Americans. J Soc Pers Relat 2004; 21: 171-85.

[http://dx.doi.org/10.1177/0265407504041373]

[43] Buss DM. The evolution of desire: Strategies of human mating. New York, NY, US: Basic Books 1994

[44] Donnelly D, Burgess E, Anderson S, Davis R, Dillard J. Involuntary celibacy: A life course analysis. J Sex Res 2001; 38: 159-69.

[http://dx.doi.org/10.1080/00224490109552083]

[45] O'Neil JM. Special issue. Men's gender conflict: 25 year research summary. J Couns Psychol 2008; 36: 358-476. [http://dx.doi.org/10.1177/0011000008317057]

[46] OECD. The OECD Better Life Index for Poland.OECD Economic Surveys: Poland. Paris: OECD Publishing 2016.

\section{(C) 2020 Ochnik \& Slonim.}

This is an open access article distributed under the terms of the Creative Commons Attribution 4.0 International Public License (CC-BY 4.0), a copy of which is available at: https://creativecommons.org/licenses/by/4.0/legalcode. This license permits unrestricted use, distribution, and reproduction in any medium, provided the original author and source are credited. 